\title{
Myeloid Responses to Extracellular Vesicles in Health and Disease
}

\author{
Priya Makhijani ${ }^{1,2}$ and Tracy L. McGaha ${ }^{1,2 *}$ \\ ${ }^{1}$ Department of Immunology, University of Toronto, Toronto, ON, Canada, ${ }^{2}$ Tumor Immunotherapy Program, Princess \\ Margaret Cancer Center, University Health Network, Toronto, ON, Canada
}

\section{OPEN ACCESS}

Edited by: David Pozo,

University of Seville, Spain

Reviewed by:

Lei Shi,

Georgia State University,

United States

Sherri L. Christian,

Memorial University of Newfoundland,

Canada

*Correspondence:

Tracy L. McGaha

tmcgaha@uhnresearch.ca

Specialty section:

This article was submitted to

Molecular Innate Immunity,

a section of the journal

Frontiers in Immunology

Received: 19 November 2021

Accepted: 15 February 2022

Published: 07 March 2022

Citation:

Makhijani P and McGaha TL (2022)

Myeloid Responses to Extracellular

Vesicles in Health and Disease.

Front. Immunol. 13:818538.

doi: 10.3389/fimmu.2022.818538
Extracellular vesicles are mediators of cell-cell communication playing a key role in both steady-state and disease conditions. Extracellular vesicles carry diverse donor-derived cargos, including DNA, RNA, proteins, and lipids that induce a complex network of signals in recipient cells. Due to their ability to capture particulate matter and/or capacity to polarize and orchestrate tissue responses, myeloid immune cells (e.g., dendritic cells, macrophages, etc.) rapidly respond to extracellular vesicles, driving local and systemic effects. In cancer, myeloid-extracellular vesicle communication contributes to chronic inflammation, self-tolerance, and therapeutic resistance while in autoimmune disease, extracellular vesicles support inflammation and tissue destruction. Here, we review cellular mechanisms by which extracellular vesicles modulate myeloid immunity in cancer and autoimmune disease, highlighting some contradictory results and outstanding questions. We will also summarize how understanding of extracellular vesicle biology is being utilized for novel therapeutic and diagnostic applications.

Keywords: macrophage, extracellular vesicle, cancer, autoimmune disease, inflammation

\section{INTRODUCTION}

Extracellular vesicles (EVs) are phospholipid bilayer-bound particles shown to be produced by all tested cell types. These cell-derived vesicles are released into the extracellular space accumulating in tissue, circulation and other fluids (1). Studies on EV cargo, subtype heterogeneity, and cell responses have shown they play diverse roles in health and disease. EV cargos include protein, DNA, mRNA, non-coding RNA and lipids from the donor cell, with specific cargo enrichment depending on cell status and EV subtype (2). The three most examined subtypes of EVs are apoptotic bodies (ABs), ectosomes and exosomes, though novel EV subtypes are still being identified. EVs can elicit potent autocrine, paracrine, and systemic responses in many cell types including in macrophages, endothelial cell, and lymphocytes (3). EV responses have been shown to regulate physiological processes including inflammation and tissue regeneration (3). Therefore, EVs are increasingly recognized as key mediators of intra- and inter-cellular communication, akin to cytokine signals. However, unlike most cytokines, EVs are highly stable and carry diverse cargo allowing EVs to drive complex responses both locally and at distant sites. Responses to EVs are dictated by many factors including capture mechanisms and physiological context. EVs are internalized via multiple mechanisms including receptor-mediated and lipid-raft mediated endocytosis, phagocytosis, and pinocytosis (3). Depending on route of internalization, EV cargo is delivered to different cellular compartments driving rapid recycling, interaction with endosomal receptors, and/or antigen 
presentation leading to different responses (4). EV responses via cell surface receptor interactions have also been reported, especially in cells that are poor at EV capture. For example, exosomal PD-L1 binds to PD-1 on the surface of T cells and TIM-4 has been shown to interact with phosphatidylserine on ABs, both driving immune suppression $(5,6)$.

In this review, we focus on EV responses in myeloid cells. Myeloid cells (e.g., macrophages, neutrophils, dendritic cells) are a key component of innate and adaptive immunity outnumbering other immune cells in most tissues. Importantly, myeloid cells can readily capture particulate materials and are key drivers and modulators of inflammation and tissue repair. Therefore, myeloid cells are likely highly responsive to EVs, driven by their receptor expression and/or capacity for phagocytosis and pinocytosis. Physiological context has become an important consideration in understanding EV responses, dictating which cargos are loaded into EVs as well as how recipient cells respond, including their capacity for uptake and stress or activation status (7). As such, EVs can serve opposing roles in autoimmunity and cancer depending on the inflammatory context. At steady-state innate cells capture EVs maintaining homeostasis and self-tolerance. In cancer, these mechanisms may function to dampen immune surveillance and promote chronic inflammation (8). EVs also play a progressive role as their systemic accumulation increases as we will later see in the example of metastasis. In autoimmunity, we see that the same EV cargo can promote the breakdown of immune tolerance driven by the inflammatory milieu.

Understanding how EVs drive physiological processes and identifying representative EV cargo signatures in pathological states is being utilized for therapeutic targeting and disease diagnosis. However, the role of EVs is only partially understood as the field of EV research is currently still in its infancy, and requires refinement in limitations of detection and isolation (1) as well as resolving contradictory results. The excitement around uncovering new biological mechanisms driven by these small particles, however, is generating rapid progress in the field. Here, we will examine what is known regarding mechanistic interactions between EV cargo and myeloid cells-defining a paradigm for understanding the mixed responses to EV cargo. We will also comment on the viability of therapeutic opportunities EVs generate, including inhibitory targeting of biogenesis and transfusion of EVs with an artificial therapeutic load and as vaccines.

\section{EV HETEROGENEITY}

There are currently three well described subtypes of EVs, differentiated by size and the cell processes responsible for their production. Apoptotic bodies are the largest and most studied class of EVs produced as a result of programmed cell death (2). Ectosomes and exosomes are smaller on average, jointly called small EVs (sEVs), and are produced by living cells. Differentiating the two sEVs, ectosomes are shed directly from the cell surface while exosomes (the smaller of the two sEV categories) originate from the cellular lumen bearing protein markers of their endocytic origin (9). The first EVs to be reported were ABs (50nm-5 $\mu \mathrm{m})$, as apoptosis was being closely studied in the 1960s (10). Microparticles (MPs, 50nm-1 $\mu \mathrm{m}$ ), also referred to as ectosomes, were first described in 1967 in the context of platelets and blood coagulation (11). The smallest EVs, exosomes $(30-150 \mathrm{~nm})$ were first identified in the early 1980 s $(12,13)$ in the study of transferrin receptor loss during reticulocyte maturation. These two sEV subtypes collectively were shown to be produced by healthy living cells of nearly all types-with EV dysfunction observed under cellular stress (14). The details of EV biogenesis have been recently reviewed elsewhere (3) and will not be covered here. Although the intracellular origin of the each EV subtype can be tracked, attempts to describe EV biogenesis and heterogeneity is confounded by overlapping size and biomarker criteria (2). Moreover, new classes of EVs are continually being identified including exophers (15), cytokine vesicles (16) and midbody remnants (17). The lack of consistent nomenclature in the field and biomarker oversimplification has driven pragmatic researchers to choose simpler terms like small and large EV to broadly understand biological functions.

\subsection{Classical and Non-Classical EV Subtypes}

Correctly characterizing and naming EVs is necessary for understanding each EV's distinct physiological role. In a recent review, Kalluri and LeBleu streamline EVs into two categories, EVs shed from the plasma membrane of the cell as ectosomes, and EVs originating from intracellular compartments as exosomes (9). While this system works for such classical EVs, other particles must be included as non-classical subtypes (Figure 1). Specifically, this taxonomic classification of EVs does not fully capture EV heterogeneity, especially pertaining to large EVs. While some large EVs like oncosomes $(<10 \mu \mathrm{m})$, shed from the membrane of amoeboid tumor cells, fit into their system as ectosomes, ABs and exophers do not (18). ABs can neither be characterized as large or small EVs because of their wide size range nor as ectosomes or exosomes produced by live cells because they are formed out of complete cell components from dying cells. Also, the $4 \mu \mathrm{m}$ exophers described recently in cardiomyocytes (15) and neurons (19), though containing intracellular mitochondrial components are too large to meet the exosome biogenesis criteria. Since exosome production involves formation of intraluminal vesicles (ILVs), exosomes are limited to ILV size between 30nm and 150nm (2). Further, Nicolás-Ávila et al. predict that production of exophers is related to autophagy dependant waste removal of abnormal mitochondria and protein, while exosomes are considered active agents of cell communication-although this has proven difficult to confirm. The authors also highlight that exophers are unrelated to $\mathrm{ABs}$ since apoptosis is not expected in quiescent cardiomyocytes or neurons. To enable accurate classification of such particles and to attribute responses correctly, we must include both exophers and ABs into the taxonomy of EVs. Inclusive criteria allow better resolution between particles, prevent misclassification, and can improve our understanding of complex EV responses. 


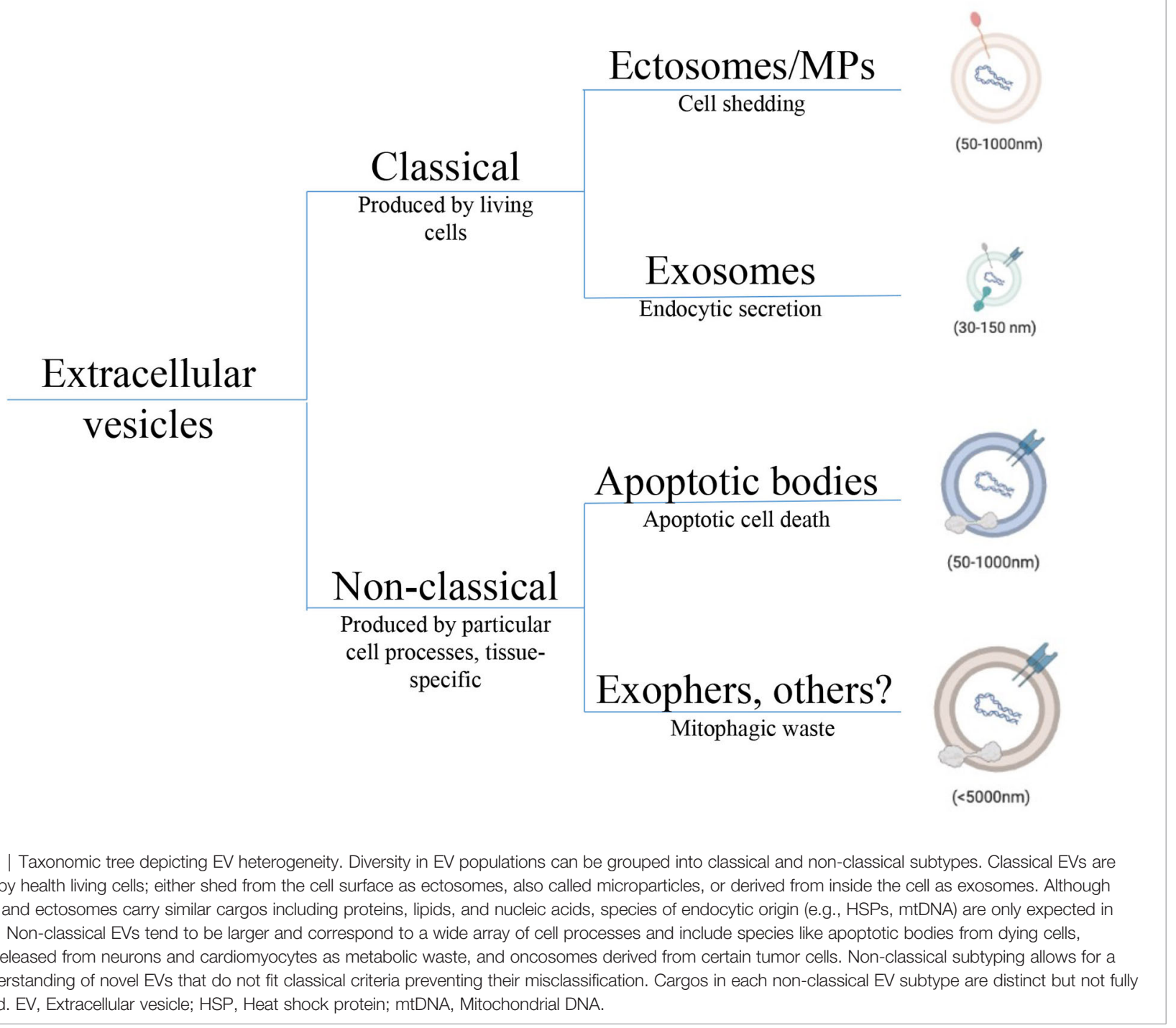

To create consistency across different EV subtypes, the minimal information for studies of extracellular vesicles (MISEV) 2018 statement recommended the use thorough biomarker characterization of EVs (20). However, authors also acknowledge that defining EVs by biomarkers that reflect their biogenesis also leads to significant overlap between EV subtypes. Importantly, this limits tracking of EVs in vivo resulting in a lack of knowledge on rates of production and physiologically relevant EV concentrations. Consequently, most studies rely on in vitro derived EVs from a single cell or body fluid source used for treatment in vitro or for in vivo transfer. $\mathrm{EV}$ isolation methods rely on size- and density-based ultracentrifugation, sizeexclusion columns, polyethylene glycol precipitation or microfluids-based immunoprecipitation, with each method yielding a partially pure EV population (1). Although small (s) EVs and be easily separated from large (l)EVs using these isolation methods, sEV isolation results in co-precipitation of other species in biofluid or media $(16,21)$. Heterogenous EV preparations confound our understanding of EV cargo signatures as well as cellular responses to EV treatment. More sophisticated isolation procedures, definitive biomarkers, basic biogenesis research, and nanoscale experimentation will be required for progress in this field. In the meantime, these limitations must be considered while studying the role EVs play in physiological processes.

\section{TUMOR EVS AND MYELOID-DRIVEN INFLAMMATION}

The heterogeneous cell populations in solid tumors and hematological malignancies produce a diversity of $\mathrm{EV}$ populations, changing by disease stage and therapeutic intervention. Understanding the diversity of $\mathrm{EV}$ populations within the tumor microenvironment (TME) as well as their nuanced effects on tumor pathology has been confounded by 
isolation and biomarker limitations. However, extensive characterization of immune responses to EVs in multiple cancer models have revealed the key role EVs play in chronic inflammation and immune tolerance. Innate immune cells are often abundant in the TME and express a wide array of receptors that capture or interact with EV particles suggesting that EVs regulate immunity by impacting innate immune function in the local tumor milieu. Supporting this prediction, studies have shown blocking EV production by tumor cells correlates with decreased overall immune responses in the TME (5) and increased myeloid cell infiltration, suppressive polarization, and differentiation (22-24) In this section, we will describe known molecular mechanisms of tumor EVs driven dysfunction in myeloid immune cells promoting chronic inflammation and immune tolerance in the tumor.

\subsection{EV Dysfunction in the Tumor Microenvironment}

Addressing the role EVs play in tumor pathophysiology begins with understanding the nature of EV production in the TME. While increased plasma EV concentration in cancer patients compared to healthy donors has been reported for many tumor types (25), production of EVs by the tumor and tumorassociated cells cannot be directly confirmed with current methodology. However, several studies suggest that tumorassociated cells produce higher levels of EVs with unique molecular signatures. EV biogenesis genes like Rab27 are upregulated in tumors and associated with poor prognosis (26). Further, hypoxia (27-30) and the cytokine milieu (e.g. IFN $\gamma, \mathrm{TGF} \beta)$ in the TME modulate EV biogenesis and cargo loading (31). Basal levels of stress $(7,14)$ and therapeutic interventions like radiation (32) can also alter EV levels and composition. The normal response to stress via the tumor suppressor p53 was shown to drive exosome biogenesis via the TSAP6 protein, suggesting abnormal exosome production by p53 mutated tumor cells (33). Activating KRAS mutations, found in many different tumor types, have been shown to control miRNA loading into exosomes. McKenzie et al. found lower levels of let-7a miRNA packaged into exosomes when Ago2 is phosphorylated by the activated KRAS (34). Let-7a miRNA has been show to target KRAS with decreased levels been reported in KRAS and BRAF tumors (35). Furthermore, high levels of let-7a were shown to promote anti-tumor microglia activation (36), suggesting a role for exosomes on innate myeloid cell responses. Together, tumor mutations and TME stimuli may drive a unique EV signature impacting systemic and local tumor immune responses.

\subsection{EVs and the Tumor Wound Hypothesis}

Tumor promoting inflammation and immune suppression in the TME has been understood by drawing parallels between the tumor and healing wound (37). In the "tumor wound" concept, the TME hijacks wound healing mechanisms driving immunosuppressive and reparative stages of inflammation without resolution stage, resulting in a chronic wound-like state. In injured tissue damaged cells release a wide range of damage-associate molecular patterns (DAMPs) including heat shock proteins (HSPs), Glypicans, HMGB1, mitochondrial DNA (mtDNA) driving the production of alarmins (IL-1, IL-33) and other effectors that recruit and activate immune effectors via pattern-recognition receptors (PRRs) (38). In the TME, tumorderived DAMPs can include mitochondrial components released due to the Warburg effect, miRNA and HSPs released due to genetic mutations and other factors like hypoxia. These DAMPs have been widely reported in tumor EVs across many tumor models (Table 1) and can drive inflammation in the tumor. In the healing wound, other signals from the unvascularized repairing tissue, hypoxia for example, drive a switch from acute inflammation to tolerance, where alternatively activated myeloid cells promote the immunosuppressive, pro-angiogenic and fibrotic stages of wound healing. A growing tumor is similarly supported by the suppression of anti-tumor immunity, angiogenesis and fibrosis. The mechanisms that sustain tumor growth in an unresolving state are not fully understood. However, the continuous exposure to EV-DAMPs to myeloid cells poised for particle capture, may contribute to tumor promoting inflammation. The signalling pathways stimulated upon EV exposure point to a key role of EVmediated induction of tumor promoting inflammation.

TABLE 1 | Examples of EV cargo effects on signalling in myeloid cells.

\begin{tabular}{lll}
\hline Cargo & \multicolumn{1}{c}{ Species } & \multicolumn{1}{c}{ Function on myeloid immune cells } \\
\hline DNA & gDNA Micronuclei (39) & Cytoplasmic STING activation in dendritic cells \\
& mitoDNA (40) & Endosomal TLR9-mediated suppressive macrophage polarization \\
RNA & YRNA (41) & STAT3-mediated MDSC activation \\
& OSRNA (42) $(43)$ & TLR7 mediated PDL-1 upregulation in monocytes \\
& IncRNA-HOTAIRM1 (44) & TLR3-mediated neutrophil recruitment at metastatic sites \\
Mitochondria & Cardiac autophagy (15) & MDSC expansion via STAT3 \\
Lipids & Phosphatidylserine (45) & Phagocytic clearance by macrophage supports tissue homeostasis \\
Cytokines & TGF- $\beta 1$ (46) & Receptor-mediated regulatory macrophage polarization \\
Self-antigen & MART1 (47) & Dendritic cell driven T cell suppression \\
Checkpoint molecules & PDL1 (5) & Delivery of tumor antigen to activated dendritic cells \\
Integrins & Tissue specific integrin signature (48) & Delivery of PDL1 to myeloid cells leads to systemic T cell exhaustion \\
Microbiome components & Gram negative cell wall components (49) & Integrins prime Kuppfer cells for liver metastasis \\
& & TLR-4 ligands in bacterial EVs activate innate immune cells
\end{tabular}




\subsubsection{Vesicular TLR-Ligand Driven Inflammation}

Myeloid cells express a battery of pattern-recognition receptors including Toll-like receptors (TLR), retinoic-acid inducible gene (RIG-I), and stimulator of interferon genes (STING) that are highly responsive to DAMPs allowing rapid immune reactivity to tissue injury (50). In the tumor, EV-DAMPs have been shown to engage both plasma membrane-localized TLRs (e.g., TLR2 and TLR4) and endosomal TLRs (e.g. TLR3, 7, and 9) driving potent responses via the transcription factor, NFKB (51). In breast cancer, palmitoylated proteins in tumor EVs can act as TLR2 ligands leading to upregulation of proinflammatory cytokines and chemokines including CCL2, IL-6 and GCSF in macrophages (52). TLR2 ligand, HMGB-1 was also found in lung cancer and shown to drive NF- $\mathrm{KB}$-dependent metabolic reprogramming of macrophages at metastatic sites (53). Also using a lung cancer model, Fabbri et al. demonstrated that exosomal miRNAs (i.e. miR-21 and miR-29a) induce IL-6 and TNF $\alpha$ in macrophages via a TLR7-NFKB dependent mechanism promoting inflammation and metastasis (54). Similarly, exosomal RNA can activate TLR3 promoting neutrophil recruitment at metastatic sites via induced expression of CXCL chemokines (43). To offer further insight into which RNA species are EV associated, an atlas of vesicular and nonvesicular RNA from healthy biofluids was recently published (55). In pancreatic cancer, sEVs from were shown to carry genomic dsDNA (56) that act as a TLR-9 ligand activating myeloid cells (57). However, Jeppesen et al. showed that genomic dsDNA-TLR9 ligands are secreted from tumor cells independent of exosomes, while HSP-TLR2 and RNA-TLR7 ligands are enriched in sEVs (21). Jeppesen et al. argue that genomic DNA (gDNA) does not exist in the same subcellular location for endosomal loading required for exosome biogenesis. However, gDNA may become exosome associated, adhering to positively charged EVs prior to capture by donor cells. The presence of double stranded mitochondrial DNA (mtDNA) is less controversial due to subcellular location. MtDNA has been observed in breast and prostate cancer EVs at higher concentrations that noncancer epithelia (58). Although transfer of mt-DNA between cell types is likely EV-mediated, most researchers have studied the role of mt-DNA alone. Mt-DNA has been shown to induce TLR9-mediated NF- $\kappa B$ activation driving regulatory polarization in macrophages in liver cancer (59) as well as activation of neutrophils in various forms of injury (60). Further, non-immune cancer-associated fibroblasts were also shown respond to mt-DNA via TLR-9 contributing to therapeutic resistance to taxanes (40). In addition to inflammatory modulation, mutations in tumor mt-DNA can also regulate mitochondrial metabolism in recipient cells (61) but have not been well-studied in the context of myeloid immunity. Size-based EV isolation procedures leading to the coprecipitation of non-vesicular nucleic acids and other molecules will confound data on EV-mediated gene induction until more specific isolation methods are found.

DAMP-TLR activation in myeloid cells can drive both proinflammatory and regulatory responses via mechanisms that are not fully understood. One hypothesis is that pro-inflammatory effectors are expected to drive pleiotropic effects on immune cells and other cells of the body, supporting both inflammatory and suppressive responses in a context dependent manner. In the context of macrophages in chronic conditions, experts have encouraged a spectrum polarization model over the dichotomous M1-M2 model, which better describes acute conditions. This integrative spectrum model also allows for a better understanding of chronic inflammation driven by tumor EVs. Interestingly, EV studies described here show upregulation of both pro- and anti-inflammatory cytokines and effectors in myeloid cells pointing to concomitant responses to mixed EV cargo. Secondly, chronic exposure to TLR ligands drives negative feedback mechanisms that lead to reduced inflammatory cytokine and increased regulatory cytokine production. Repeat treatments with DNA drive tolerance in macrophages via TLR-9 as seen by reduced TNF $\alpha$ production (62), mimicking the chronic nature of EV responses. This chronic exposure to TLR ligands is also expected to dictate hematopoietic outcomes starting in the bone marrow, driving a myeloid differentiation bias leading to reduced lymphoid to myeloid ratios in blood (63), with trained immunity being a common feature of aging and cancer pathophysiology (64).

\subsubsection{STAT3 Driven Inflammation}

Upon TLR activation of NFKB transcriptional program a further activation of STAT3 is driven by autocrine IL- 6 stimulation, in turn amplifying the overall inflammatory response (65). Chalmin et al. demonstrated the TLR2 ligand Hsp70, found on the exosome surface, activates STAT3 in MDSCs via autocrine action of IL-6 (66). These activated MDSCs produce IL-10 and upregulate arginase 1 activity inhibiting $\mathrm{T}$ cell proliferation. The EV-driven IL-6-STAT3 axis was also shown to keep bone marrow precursors in an immature state inhibiting the differentiation to mature DCs capable of anti-tumor responses (24). A STAT3 regulatory signature was also observed in monocytes treated with glioblastoma exosomes correlating with increased interferon- $\gamma$ production (67). A similar TLR2/4STAT3 response driven by HSPs was seen in bone marrowderived dendritic cells (BMDCs) promoting a pro-tumor IL-6, PGE-2, IL-1, and TNF response after exosome treatment (68).

EVs have also been shown to control the NFKB-STAT3 axis via the action of specific miRNA cargo. Both NFKB-driven and exosomal $m i R-21 a$ was shown to silence PDCD4, a tumor suppressor and IL-6 inhibitor, promoting the expansion of MDSCs in a IL-6/STAT3 dependant manner in lung cancer (69). Exosomal $m i R-106 b$ found in colorectal cancer also suppresses PDCD4 driving both IL-6/STAT3 and mTOR signalling to promoting regulatory polarization in tumor macrophages (70). The exosomal $m i R-222-3 p$ in ovarian cancer, has been shown to silence SOCS3 in monocytes promoting a STAT3-mediated regulatory signature in macrophages including Arg1 and CD206 expression (71). It is not clear whether the concentration of miRNA in sEVs can reach a local concentration capable of eliciting an immune response (72) or whether tumor derived sEVs may be continuously produced eliciting a cumulative response over time. 


\subsection{EVs and Pre-Metastatic Niche Formation}

EV-macrophage interactions have been implicated in the priming of the metastatic niche in several studies. In Hoshino et al., exosomes from tumor cell lines with a liver metastatic ability were compared to non-metastatic lines and were shown to carry integrin $\alpha_{v} \beta_{5}$. This allowed preferential binding to liver-specific cells including $\mathrm{CD} 169^{+}$ Kupffer macrophages, driving an inflammatory phenotype via integrin-mediated Src phosphorylation and upregulation of s100 and fibronectin genes (48). Similarly, in Costa-Silva et al., migration inhibitory factor (MIF) found in pancreatic cancer exosomes was taken up by Kupffer macrophages driving TGF $\beta$ and fibronectin production priming the liver for metastasis (73). In Peinado et al., the receptor tyrosine kinase MET found in melanoma exosomes was captured by bone marrow progenitors driving vasculogenesis and promoting metastasis in a systemic fashion (74). Another group studying brain metastasis, showed that miR-19a carried from astrocyte exosomes to tumor cells led to reduction of PTEN and increased CCL2 via NFKB in tumor cells driving suppressive myeloid infiltration (75). Interestingly, injection of melanoma EVs drove downregulation of IFNAR1 in monocytes at distant sites driving lung metastasis via fibronectin deposition (76). This downregulation of IFNAR was thought to dependent on p38 expression driven by exosomal mRNA mediated TLR3-NFKB activation $(43,76)$. Albeit via differing mechanisms, these studies all support the pathogenic role of distant EV-mediated cell-cell communication in tumor metastasis.

\subsection{Modulating the Interferon Response}

Activation of TLRs in myeloid cells via DAMPs drives both $\mathrm{NF \kappa B}$ and interferon regulatory factor (IRF) signalling. However, several studies suggest tumor EVs may inhibit interferon (IFN) expression and IFN responses. In an elegant approach, Gao et al. injected tumor derived exosomes into mice infected with both DNA and RNA viruses to examine EV-driven immune suppression. The data showed that exosome-delivered epidermal growth factor receptor (EGFR) reduced INF $\beta$ expression in macrophages after viral infection (77). Mechanistically, this was the result of tumor EV-EGFR driven Mitogen-Activated Protein Kinase Kinase Kinase 2 (MEKK2) phosphorylation, inhibiting IRF3 dimerization and IFN production. Similarly, hepatocarcinoma EVs containing interferon induced transmembrane Protein 2 (IFITM2) reduced IFN $\alpha$ production by $\mathrm{HBV}$ infected dendritic cells (78) while exosome delivered IRF2 (IRF2 is a repressor of Type I IFN signaling) limited IFN $\alpha / \beta$ production in macrophages. EVs can also directly reduce cellular responsiveness to IFN stimulation. For example, melanoma EVs can directly down-regulate interferon alpha and beta receptor 1 (IFNAR1) in myeloid cells via 338 activation dampening responsiveness to IFN stimulation (76). IFNAR downregulation was also required for maintaining suppressive activation in MDSCs (79). Thus, cumulatively the data suggests EV exposure can have wide ranging impact on IFN response influencing initial stimulation and downstream IFNinduced transcriptional programs.
EVs produced by tumors also contain self-associated molecular patterns (SAMPs) that potentially modulate tumor inflammation by molecular pathways that are distinct from those described above (80). The siglec-family self-pattern recognition receptors (SPRRs) bind to self-sialic acid residues abundant on EVs (81). Hypersialyation has been reported in both solid tumors and hematological malignancies (82) with sialic acid enrichment on tumor EVs (83). These surface glycans are required for EV internalization by many cell types (83). For example, CD169 (also known as Siglec-1 or sialoadhesin) is an exosome endocytic receptor for macrophages by binding $\alpha 2,3$-linked sialic acids (84). CD169 is expressed on sentinel macrophages at key interfaces in the body (blood-spleen, fetal-maternal, lung-air, etc). In peripheral lymphoid organs, $\mathrm{CD} 169^{+}$macrophages play a key role in orchestrating the response to particulate antigens including $A B s$ and virus particles (85-87). Infection with vesicular stomatitis virus (VSV) induced CD169 upregulation and recruitment of a DAP12/SHP2/TRIM27 complex (88). This inhibitory complex ubiquitinated and degraded TBK1, inhibiting IRF3 phosphorylation and downregulating the type I IFN response (88). Because CD169 is an IFN stimulated gene (ISG) this mechanism may be a negative feedback loop, promoting tolerance to self-sialic acids. Supporting this concept, in a mouse model of HIV, CD169 deletion lead to better control of viral load with increased IFN-I production (86). Other siglec family receptors (e.g. Siglec-H, Siglec-G and Siglec-10) also contain immunoreceptor tyrosine-based inhibitory motifs (ITIMs) or recruit adaptor proteins with ubiquitinase activity, with the exception of CD33 and Siglec-H which have activating function (82). Binding of EV sialic acids to siglecs may similarly attenuate IFN responses, modifying the overall effect of EV-DAMP signalling via TLR $(89,90)$. Specifically, myeloid siglec-7 and siglec-9 have been shown to reduce HLA-DR and CD86 expression upon engagement with tumor-derived sialic acids promoting $\mathrm{T}$ cell suppression in the pancreatic TME (91). Siglec ${ }^{+}$ macrophages were also found in the bone marrow, controlling HSC (92) and erythrocyte egress (93).

These studies collectively show that EVs package both DAMPs and other endogenous immunity-inducing structures driving diverse responses in myeloid immune cells (Figure 2). While one signal from DAMPs provides activation of TLRSTAT-NFKB pathways resulting in inflammatory cytokine production, a second signal from self-patterns and other cargo inhibits the IFN-I response attenuating inflammation and selfantigen presentation. This results in a unique EV response that promotes the breakdown of immune surveillance in cancer and prevents autoimmunity under homeostatic conditions.

\section{AUTOIMMUNE EVS PROMOTE INFLAMMATION AND TISSUE DESTRUCTION}

In cancer studies the popularity of the term "exosome" has resulted in its use as a generic descriptor of EVs despite its specific endocytic definition that precludes other EVs (94). In the field of autoimmunity, outside of apoptotic bodies that have been widely 


\section{A Distinct uptake mechanisms dictate intracellular compartment localization and response:}
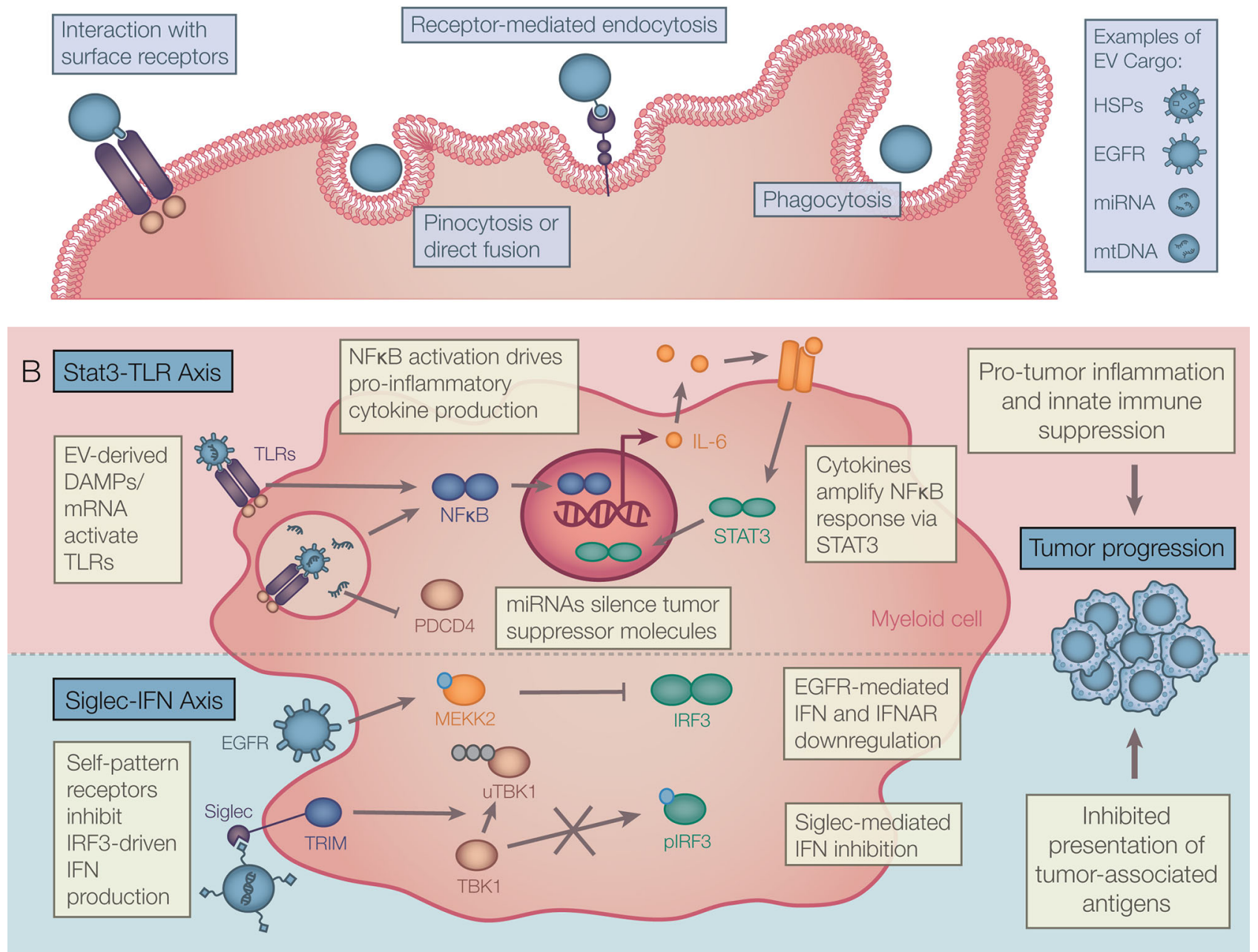

FIGURE 2 | Theoretical framework for tumor EV driven myeloid responses. (A) EV capture mechanisms include binding directly to cell surface receptors, direct fusion, and internalization by pinocytosis, receptor-mediated endocytosis, and phagocytosis. Distinct capture mechanisms deliver EV cargo to compartment-specific receptors driving diverse EV responses in recipient myeloid cells. (B) A range of tumor EV cargos act together to drive tumor promoting inflammation. Chronic interaction with EV-DAMPs and other effectors activate NF-KB and STAT3 signalling resulting in accumulation of late-stage cytokines. Also, self-molecular patterns and other effectors found in EVs attenuate type I IFN production and/or response. These signals can modulate acute inflammation and presentation of tumor antigens. EV, Extracellular vesicle; DAMPs, Danger-associated molecular patterns; NF-kB, Nuclear factor Kappa B; STAT, Signal transducer and activator of transcription; IFN, Interferon.

studied, the term microparticle (MP) is more prevalent in the study of sEVs. Because in vitro derived MPs mainly use lower centrifugation speeds, these studies capture larger vesicles, enriching the ectosomal or cell shedding EV phenotype. MPs also lack endocytic markers like chaperone HSPs and are enriched in phosphatidylserine (95). Exosomes, have also been studied in autoimmunity, however, the role they play distinct from other sEV subtypes is not clear.

Many of the same EV cargo components have been found in cancer and autoimmunity. Similar to observations in cancer EVs, higher levels of EVs have been reported in Sjögren's syndrome, systemic lupus erythematosus (SLE) and rheumatoid arthritis (RA) compared to healthy individuals $(96,97)$. Here too, the presence of DAMPs in EVs drives inflammation in a TLR-dependent manner. The focus in autoimmune disease has been on the TLR7 and TLR9 ligands DNA and RNA which are abundant in sEVs and apoptotic bodies found at high concentrations in circulation (98). We have previously reviewed the systemic effects of ABs in SLE (99), and will focus on the role of sEVs in this review. Exosomal miR-let-7b found in RA synovial fluid, promoted TLR7 activity in myeloid cells of inflamed joints, stimulating production of IL-1 $\beta$ and IL-6 (100). Further, removal of DNA from EVs by circulating DNASE1L3 prevents autoimmunity in healthy mice, while in lupus, DNASE1L3 null mutations and the presence of anti-DNA autoantibodies 
protects against DNA degradation promoting inflammation in a TLR-MyD88-dependent, STING-independent mechanism (101). HMGB1 has also been found in autoimmune EVs and functions to promote inflammation via TLR4 in myeloid cells (102). In these studies, sources of EVs were varied, arising from platelets, endothelial cells, fibroblasts, and dying lymphocytes. A similar mechanism was also observed in scleroderma (103). EVs were also found as immune-complexes (ICs) with the anti-DNA/RNA autoantibodies characteristic of RA and SLE, promoting complement-driven, TLR-mediated DC inflammatory activation (104). EVs were also shown to contain citrullinated self-proteins contributing to the formation of inflammatory immune complexes in SLE and RA, driving monocyte and macrophage activation (105, 106). In lupus, ICs were required for a metabolic switch to glycolysis in macrophages leading to production of IL1 and ROS (107), further exasperating autoimmunity.

In type 1 diabetes (T1D) pancreatic $\beta$-cell specific destruction is triggered, rather than the systemic tissue destruction seen in SLE. Because EV release occurs prior to immune $\beta$-cell destruction, EVs may play a role in disease initiation. Using in vitro derived $\mathrm{EV}$ s from MSC-like cells from the NOD pancreas, Rahman et al. show that the intrinsic endoplasmic reticulum stress in cells of the pre-diabetic pancreas controls EV cargo driving DC-mediated priming of autoreactive T and B cells via IFN $\gamma$ upon EV treatment (108). Moreover, the T1D autoantigens glutamic acid decarboxylase 65 (GAD65), zinc transporter 8 (ZnT8), and $\beta$-cell resident glucose transporter 2 (Glut2) were found within T1D islet EVs (109), supporting both the EV delivery of self-antigen as well as autoantibody-EV immune complex driven myeloid cell activation via $\mathrm{F}_{\mathrm{c}}$ receptors. Micro RNA species have also shown to play a key role in T1D pathogenesis. In addition to targeting many metabolic genes, the exosomal miR-29 derived from $\beta$-cells, also found in tumor exosomes, also induces TLR7-MyD88 dependent inflammatory cytokine production, including IFN-I responses (110). Exosomal miR-29 has also been found at higher levels in type 2 diabetes, driving metabolic reprogramming of macrophages via TRAF3 promoting systemic insulin resistance (111). Like observations in cancer and systemic autoimmune diseases, EVs appear to largely promote inflammation in T1D. However, EV-driven protection from autoimmunity has also been reported. AhR ligands found in EVs and other endogenous sources, attenuate autoimmunity in cases of EAE and lupus $(98,112)$.

The inflammatory context in autoimmunity and cancer lead to myeloid responses to the same EV cargo to both break tolerance and suppress immune responses via mechanisms that remain elusive. Studies on differences in EV concentration and IFN induction by autoimmune EVs versus tumor EVs may offer insights into how this is achieved.

\section{EVS AND THERAPEUTIC OPPORTUNITIES}

The most readily apparent application for EVs is their potential as diagnostic tools. Since they contain biomarkers of cell status, EVs from blood, ascites, and urine can potentially be utilized to serve as a liquid biopsy diagnostic differentiating healthy from diseased states. Targets including metabolic peptides, nucleotide species including circulating tumor (ct)DNA, autoantibody immune complexes and microbiome-derived EV cargo are being actively explored for diagnostic purposes $(25,113)$. Though finding EV biomarkers that differentiate related disease states have proven difficult, this line of investigation may be useful for both cancer and systemic autoimmune conditions $(114,115)$. A thorough review of EV cargo biomarkers being investigated for diagnostic application can be found elsewhere (116).

As detailed in this review, EVs promote inflammation and disease pathophysiology by variety of different mechanisms. Therefore, the inhibition of EV biogenesis using small molecules agents is being explored as a therapeutic opportunity in both cancer and autoimmunity. Small molecules including GW4869 and dimethyl amerlioride, as well as siRNA against proteins in EV biogenesis pathways, have been used extensively for research and hold promise in targeting pro-tumor inflammation driven by EVDAMPs. However, each of these molecules have exhibited off-target effects on cellular physiology; for example, GW4869 which targets neutral sphingomyelinase (N-SMase) can also have effects on autophagy (117). Datta et al. have validated novel exosome inhibitors using prostate cancer cells, identifying natural small molecules like Forskolin and antibiotics like Manumycin A as blockers of exosome biogenesis (118). Rab-GTPase inhibitors, along with other anti-tumor functions on tumor growth and cytokine secretion, can also antagonize EV biogenesis and can be used therapeutically (119). The design and delivery of siRNA against proteins involved in biogenesis like Rab27a/b in the case of exosomes may allow for more specific targeting than small molecule inhibitors (120). However, to identify the best therapeutic target with the fewest off-target effects, a more comprehensive understanding of both EV responses and biogenesis pathways is required.

The targeting of EV capture and response by myeloid immune cells is another strategy to attenuate chronic inflammation in both cancer and autoimmunity. As described earlier, the siglec-sialic acid axis may antagonize IFN-mediated tumor destruction. Several antisiglec antibodies are being investigated including anti-siglec-7 and anti-siglec-33 which target NK cells and immature myeloid cells respectively attenuating their regulatory function (121). Targeting other siglecs and scavenger receptors may lead to the abrogation of EV capture or facilitate delivery of therapeutical active EV cargo. EV-CD169 interactions in macrophages also drive antigen presentation in the context of infection and chemotherapy (86, 87). Capitalizing on this observation, Edgar et al. show that liposomes containing antigens targeted to CD169 via decoration with sialic acid residues induces CD4 T cell responses, but requires liposome loading with high-doses of TLR7-IFN promoting adjuvant for cytolytic CD8 T cell responses (122). The myeloid responses to EV-DAMPs can be inhibited via the targeting of the TLR-NFאB pathways. Though this is promising in autoimmunity, in cancer TLR agonism is being investigated in the clinic due to its ability to promote tolerance to the tumor (123). However, TLR4 driven myeloid tolerance has also been blamed for paclitaxel 
resistance which acts as a TLR4 agonist (124). Inhibiting this pathway in cancer may involve timing where, as a neoadjuvant strategy, EV-DAMP driven NFKB activation can be inhibited temporarily prior to $\mathrm{T}$ cell activation or chemotherapy. Lastly, to promote MHC loading of tumor neoantigen in APCs after EV capture, an interesting recycling regulator Rab17 (shown to prevent presentation of $\mathrm{AB}$ derived self-antigens) could be targeted to promote tumor-specific immune destruction (125). Because EVmyeloid cell interactions are also part of homeostatic processes, targeting EV biogenesis, capture and responses to EVs may drive off-target effects that remain to be fully understood in in vivo disease contexts.

Furthermore, the administration of bioactive EVs is being investigated in various therapeutic strategies. The use of EVs for delivery is advantageous over liposomes with the ability to easily disguise as self in the body. Moreover, EVs decorated with integrins can target specific tissue sites allowing for specific delivery of therapeutic cargo (48). In mice, exosomes loaded with IL-12 (exoIL2) were shown to promote an antitumor $\mathrm{T}$ cell response, superior to the recombinant cytokine alone due to the improved pharmacokinetics (126). Because IFN signalling in APCs drives antigen presentation and cross presentation to both CD8+ and CD4+ T cells (127), therapeutic administration of large doses of EVs loaded with STING agonist dinucleotides (exoSTING) is being explored to promote adaptive anti-tumor immune responses. Jang et al. showed that exoSTING exerts tumor control by targeting APCs preferentially which induces antitumor $\mathrm{T}$ cell responses with long-term memory $\mathrm{T}$ cell induction (128). Although STING and RIG-I activation has been reported in dendritic cells, and other cells stimulated by EVs $(129,130)$, it may be attenuated downstream by Siglec-TBK1-dependant mechanisms in vivo. Limiting IFN-driven antigen presentation in response to DAMP-containing EVs may be an evolutionary mechanism to limit excessive self-peptide presentation and autoimmunity, also serving to limit tumor neoantigen presentation. Modulating the dose of EVs and additional modifications to such therapeutically administered EVs, like sialidase treatment might circumvent regulatory immune responses. In autoimmunity, these administered EVs can functions as decoys to autoantibodies. Casella et al. showed that EVs from oligodendrocytes contain myelin and related antigens and can be used to subvert myelin destruction in a model of multiple sclerosis (131). The applications for decorating or loading EVs with many different cell-targeting or immunomodulatory agents suggest EVs could be utilized as versatile payload delivery agents.

EVs have also been explored as cell-free anti-tumor vaccines. Specifically, vaccination with exosomes derived from tumor antigen loaded DCs reduced tumor burden by induction of anti-tumor T cell responses (132). DC-derived sEVs can carry whole tumor associated antigens (TAAs), TAA peptide-loaded $\mathrm{MHC} / \mathrm{HLA}$, and co-stimulatory signals significantly improving vaccination efficacy compared to whole tumor lysate vaccination (133). However, the requirement of MHC molecules for functionality/immune responses to DC-derived EVs (DEX) is not clear. For example, Hiltbrunner et al. reported that whole antigen in the absence of MHCI and II is sufficient to induce a DEX-mediated $\mathrm{T}$ cell response suggesting internalization and antigen processing are the key relevant components for EVdriven immune responses (134). Supporting this prediction, DEX loaded with antigen can drive stronger in vivo $\mathrm{T}$ cell responses than DC-EVs from an ectosomal origin, suggesting an involvement of the endocytic compartment in the efficacy of DEX (135). The clinical success of DEX as vaccines will likely require large, non-physiological doses of EV particles which necessitated the large-scale culture of donor-matched DCs potentially limiting this approach. In contrast to DEX, the application of the more readily available tumor EVs is currently limited to DC vaccines primed with tumor EVs. Andre et al. show that exosomes isolated from melanoma ascites contain TAAs like MART1 and gp100, and when used to stimulate donor-matched dendritic cells promote antigenspecific $\mathrm{T}$ cell activation and cytolytic function in vitro (47). Further. the in vivo injection of DCs treated with in vitro tumor cell-derived EVs into tumor-bearing mice was reported to drive tumor rejection in a T cell-dependent manner (136). These DC vaccine strategies are similarly challenged with the culture and dosing of DCs at therapeutic concentration as well as HLAmatching of both EVs and DCs required to induce the desired anti-tumor response. The pre-dominantly immunosuppressive role for tumor EVs is supported by a large body of literature and suggests the direct use of tumor-derived exosomes as TAA containing vaccines may not be a readily applicable approach given our current level of understanding.

\section{CONCLUSION}

Extracellular vesicles take on a wide heterogeneity of subtypes and relay a specific molecular signature from their cell of origin. The effects of a diverse EV cargo on myeloid immune cells are revealing their role in inflammation and diseases of immune dysregulation including cancer and autoimmunity. In the tumor, context dependant mechanisms drive a pro-tumor inflammation both locally and at metastatic sites promoting a breakdown of immune surveillance, whereas in autoimmunity, mechanistically similar EV signals promote a breakdown of tolerance and autoimmune pathology. Importantly, EVs are potent modulators of the IFN response which may provide protective function preventing autoimmunity, but also provide a significant barrier to anti-cancer immunity. EVs are more biologically complex compared to other cell-cell communication systems (e.g., cytokines) and this complexity has provided a barrier to our understanding, but also opportunities to harness EV biology for therapy. In this vein, the clinical application of EVs is numerous including disease diagnosis/prognosis, engineered delivery of therapeutic cargo, and administration of anti-tumor vaccines. Ultimately, these therapeutic strategies hold great promise but require much more research for safe and effective execution. In the final analysis, although great strides towards the understanding of EVs have been made, this burgeoning field 
promises to reveal novel cellular mechanisms involved in health and disease.

\section{AUTHOR CONTRIBUTIONS}

PM and TM conceived the manuscript. All authors contributed to the article and approved the submitted version.

\section{REFERENCES}

1. Cocozza F, Grisard E, Martin-Jaular L, Mathieu M, Théry C. SnapShot: Extracellular Vesicles. Cell (2020) 182:262-262.e1. doi: 10.1016/ j.cell.2020.04.054

2. Colombo M, Raposo G, Théry C. Biogenesis, Secretion, and Intercellular Interactions of Exosomes and Other Extracellular Vesicles. Annu Rev Cell Dev Biol (2014) 30:255-89. doi: 10.1146/annurev-cellbio-101512-122326

3. Mathieu M, Martin-Jaular L, Lavieu G, Théry C. Specificities of Secretion and Uptake of Exosomes and Other Extracellular Vesicles for Cell-to-Cell Communication. Nat Cell Biol (2019) 21:9-17. doi: 10.1038/s41556-0180250-9

4. Horibe S, Tanahashi T, Kawauchi S, Murakami Y, Rikitake Y. Mechanism of Recipient Cell-Dependent Differences in Exosome Uptake. BMC Cancer (2018) 18:47. doi: 10.1186/s12885-017-3958-1

5. Poggio M, Hu T, Pai C-C, Chu B, Belair CD, Chang A, et al. Suppression of Exosomal PD-L1 Induces Systemic Anti-Tumor Immunity and Memory. Cell (2019) 177:414-27.e13. doi: 10.1016/j.cell.2019.02.016

6. Wong K, Valdez PA, Tan C, Yeh S, Hongo J-A, Ouyang W. Phosphatidylserine Receptor Tim-4 Is Essential for the Maintenance of the Homeostatic State of Resident Peritoneal Macrophages. Proc Natl Acad Sci (2010) 107:8712-7. doi: 10.1073/pnas.0910929107

7. Harmati M, Gyukity-Sebestyen E, Dobra G, Janovak L, Dekany I, Saydam O, et al. Small Extracellular Vesicles Convey the Stress-Induced Adaptive Responses of Melanoma Cells. Sci Rep (2019) 9:15329. doi: 10.1038/ s41598-019-51778-6

8. Willms E, Cabañas C, Mäger I, Wood MJA, Vader P. Extracellular Vesicle Heterogeneity: Subpopulations, Isolation Techniques, and Diverse Functions in Cancer Progression. Front Immunol (2018) 9:738. doi: 10.3389/fimmu.2018.00738

9. Kalluri R, LeBleu VS. The Biology, Function, and Biomedical Applications of Exosomes. Science (2020) 367:640-1. doi: 10.1126/science.aau6977

10. Kerr JF, Wyllie AH, Currie AR. Apoptosis: A Basic Biological Phenomenon With Wide-Ranging Implications in Tissue Kinetics. Br J Cancer (1972) 26:239-57. doi: 10.1038/bjc.1972.33

11. Wolf $P$. The Nature and Significance of Platelet Products in Human Plasma. Br J Haematol (1967) 13:269-88. doi: 10.1111/j.1365-2141.1967.tb08741.x

12. Harding C, Heuser J, Stahl P. Receptor-Mediated Endocytosis of Transferrin and Recycling of the Transferrin Receptor in Rat Reticulocytes. J Cell Biol (1983) 97:329-39. doi: 10.1083/jcb.97.2.329

13. Pan BT, Johnstone RM. Fate of the Transferrin Receptor During Maturation of Sheep Reticulocytes In Vitro: Selective Externalization of the Receptor. Cell (1983) 33:967-78. doi: 10.1016/0092-8674(83)90040-5

14. Fleshner M, Crane CR. Exosomes, DAMPs and miRNA: Features of Stress Physiology and Immune Homeostasis. Trends Immunol (2017) 38:768-76. doi: 10.1016/j.it.2017.08.002

15. Nicolás-Ávila JA, Lechuga-Vieco AV, Esteban-Martínez L, Sánchez-Díaz M, Díaz-García E, Santiago DJ, et al. A Network of Macrophages Supports Mitochondrial Homeostasis in the Heart. Cell (2020) 183:94-109.e23. doi: 10.1016/j.cell.2020.08.031

16. Fitzgerald W, Freeman ML, Lederman MM, Vasilieva E, Romero R, Margolis L. A System of Cytokines Encapsulated in ExtraCellular Vesicles. Sci Rep (2018) 8:8973. doi: 10.1038/s41598-018-27190-x

17. Rai A, Greening DW, Xu R, Chen M, Suwakulsiri W, Simpson RJ. Secreted Midbody Remnants Are a Class of Extracellular Vesicles Molecularly Distinct From Exosomes and Microparticles. Commun Biol (2021) 4:400. doi: $10.1038 / \mathrm{s} 42003-021-01882-\mathrm{z}$

\section{ACKNOWLEDGMENTS}

This work was supported by NIH grants R01AR067763, R01CA190449, the Terry Fox Research Institute New Frontiers Program, and Canadian Institutes of Health Research Project Grants (TM). We would like to thank Dr. Kieran Manion for assistance with figure preparation.

18. Morello M, Minciacchi VR, de Candia P, Yang J, Posadas E, Kim H, et al Large Oncosomes Mediate Intercellular Transfer of Functional microRNA. Cell Cycle Georget Tex (2013) 12:3526-36. doi: 10.4161/cc.26539

19. Melentijevic I, Toth ML, Arnold ML, Guasp RJ, Harinath G, Nguyen KC, et al. C. Elegans Neurons Jettison Protein Aggregates and Mitochondria Under Neurotoxic Stress. Nature (2017) 542:367-71. doi: 10.1038/nature21362

20. Théry C, Witwer KW, Aikawa E, Alcaraz MJ, Anderson JD, Andriantsitohaina R, et al. Minimal Information for Studies of Extracellular Vesicles 2018 (MISEV2018): A Position Statement of the International Society for Extracellular Vesicles and Update of the MISEV2014 Guidelines. J Extracell Vesicles (2018) 7:1535750. doi: 10.1080/20013078.2018.1535750

21. Jeppesen DK, Fenix AM, Franklin JL, Higginbotham JN, Zhang Q, Zimmerman LJ, et al. Reassessment of Exosome Composition. Cell (2019) 177:428-445.e18. doi: 10.1016/j.cell.2019.02.029

22. Bobrie A, Krumeich S, Reyal F, Recchi C, Moita LF, Seabra MC, et al. Rab27a Supports Exosome-Dependent and -Independent Mechanisms That Modify the Tumor Microenvironment and can Promote Tumor Progression. Cancer Res (2012) 72:4920-30. doi: 10.1158/0008-5472.CAN-12-0925

23. Liu Y, Xiang X, Zhuang X, Zhang S, Liu C, Cheng Z, et al. Contribution of MyD88 to the Tumor Exosome-Mediated Induction of Myeloid Derived Suppressor Cells (MDSC) (95.16). J Immunol (2010) 184:95.16-6. doi: 10.2353/ajpath.2010.090777

24. Yu S, Liu C, Su K, Wang J, Liu Y, Zhang L, et al. Tumor Exosomes Inhibit Differentiation of Bone Marrow Dendritic Cells. J Immunol Baltim Md 1950 (2007) 178:6867-75. doi: 10.4049/jimmunol.178.11.6867

25. Melo SA, Luecke LB, Kahlert C, Fernandez AF, Gammon ST, Kaye J, et al. Glypican1 Identifies Cancer Exosomes and Facilitates Early Detection of Cancer. Nature (2015) 523:177-82. doi: 10.1038/nature14581

26. Kren N, Michaud D, Bagchi S, Greene K, Pylayeva-Gupta Y. Rab27a Plays a Dual Role in Metastatic Propensity of Pancreatic Cancer. Sci Rep (2020) 10:7390. doi: 10.1038/s41598-020-64248-1

27. King HW, Michael MZ, Gleadle JM. Hypoxic Enhancement of Exosome Release by Breast Cancer Cells. BMC Cancer (2012) 12:421. doi: 10.1186/ 1471-2407-12-421

28. Li L, Li C, Wang S, Wang Z, Jiang J, Wang W, et al. Exosomes Derived From Hypoxic Oral Squamous Cell Carcinoma Cells Deliver miR-21 to Normoxic Cells to Elicit a Prometastatic Phenotype. Cancer Res (2016) 76:1770-80. doi: 10.1158/0008-5472.CAN-15-1625

29. Parolini I, Federici C, Raggi C, Lugini L, Palleschi S, De Milito A, et al. Microenvironmental pH Is a Key Factor for Exosome Traffic in Tumor Cells. J Biol Chem (2009) 284:34211-22. doi: 10.1074/jbc.M109.041152

30. Xu J, Zhang J, Zhang Z, Gao Z, Qi Y, Qiu W, et al. Hypoxic Glioma-Derived Exosomes Promote M2-Like Macrophage Polarization by Enhancing Autophagy Induction. Cell Death Dis (2021) 12:1-16. doi: 10.1038/s41419021-03664-1

31. Zhang Q, Fu L, Liang Y, Guo Z, Wang L, Ma C, et al. Exosomes Originating From MSCs Stimulated With TGF- $\beta$ and IFN- $\gamma$ Promote Treg Differentiation. J Cell Physiol (2018) 233:6832-40. doi: 10.1002/jcp.26436

32. Ni J, Bucci J, Malouf D, Knox M, Graham P, Li Y. Exosomes in Cancer Radioresistance. Front Oncol (2019) 9:869. doi: 10.3389/fonc.2019.00869

33. Lespagnol A, Duflaut D, Beekman C, Blanc L, Fiucci G, Marine J-C, et al. Exosome Secretion, Including the DNA Damage-Induced P53-Dependent Secretory Pathway, Is Severely Compromised in TSAP6/Steap3-Null Mice. Cell Death Differ (2008) 15:1723-33. doi: 10.1038/cdd.2008.104

34. McKenzie AJ, Hoshino D, Hong NH, Cha DJ, Franklin JL, Coffey RJ, et al. KRAS-MEK Signaling Controls Ago2 Sorting Into Exosomes. Cell Rep (2016) 15:978-87. doi: 10.1016/j.celrep.2016.03.085 
35. Wang X-R, Luo H, Li H-L, Cao L, Wang X-F, Yan W, et al. Overexpressed Let-7a Inhibits Glioma Cell Malignancy by Directly Targeting K-Ras, Independently of PTEN. Neuro Oncol (2013) 15:1491-501. doi: 10.1093/ neuonc/not 107

36. Buonfiglioli A, Efe IE, Guneykaya D, Ivanov A, Huang Y, Orlowski E, et al. Let-7 MicroRNAs Regulate Microglial Function and Suppress Glioma Growth Through Toll-Like Receptor 7. Cell Rep (2019) 29:3460-71.e7. doi: 10.1016/j.celrep.2019.11.029

37. Hanahan D, Weinberg RA. Hallmarks of Cancer: The Next Generation. Cell (2011) 144:646-74. doi: 10.1016/j.cell.2011.02.013

38. Foster DS, Jones RE, Ransom RC, Longaker MT, Norton JA. The Evolving Relationship of Wound Healing and Tumor Stroma. JCI Insight (2018) 3: E9991. doi: 10.1172/jci.insight.99911

39. Yokoi A, Villar-Prados A, Oliphint PA, Zhang J, Song X, Hoff PD, et al. Mechanisms of Nuclear Content Loading to Exosomes. Sci Adv (2019) 5: eaax8849. doi: 10.1126/sciadv.aax8849

40. Haldar S, Mishra R, Billet S, Thiruvalluvan M, Placencio-Hickok VR, Madhav A, et al. Cancer Epithelia-Derived Mitochondrial DNA is a Targetable Initiator of a Paracrine Signaling Loop That Confers Taxane Resistance. Proc Natl Acad Sci (2020) 117:8515-23. doi: 10.1073/pnas.1910952117

41. Huber V, Vallacchi V, Fleming V, Hu X, Cova A, Dugo M, et al. TumorDerived microRNAs Induce Myeloid Suppressor Cells and Predict Immunotherapy Resistance in Melanoma. J Clin Invest (2018) 128:550516. doi: 10.1172/JCI98060

42. Haderk F, Schulz R, Iskar M, Cid LL, Worst T, Willmund KV, et al. TumorDerived Exosomes Modulate PD-L1 Expression in Monocytes. Sci Immunol (2017) 2. doi: 10.1126/sciimmunol.aah5509

43. Liu Y, Gu Y, Han Y, Zhang Q, Jiang Z, Zhang X, et al. Tumor Exosomal RNAs Promote Lung Pre-Metastatic Niche Formation by Activating Alveolar Epithelial TLR3 to Recruit Neutrophils. Cancer Cell (2016) 30:243-56. doi: 10.1016/j.ccell.2016.06.021

44. Thakuri BKC, Zhang J, Zhao J, Nguyen LN, Nguyen LNT, Khanal S, et al. LncRNA HOTAIRM1 Promotes MDSC Expansion and Suppressive Functions Through the HOXA1-Mir124 Axis During HCV Infection. Sci Rep (2020) 10:22033. doi: 10.1038/s41598-020-78786-1

45. Matsumura S, Minamisawa T, Suga K, Kishita H, Akagi T, Ichiki T, et al. Subtypes of Tumour Cell-Derived Small Extracellular Vesicles Having Differently Externalized Phosphatidylserine. J Extracell Vesicles (2019) 8. doi: 10.1080/20013078.2019.1579541

46. Huang F, Wan J, Hao S, Deng X, Chen L, Ma L. TGF- $\beta 1$-Silenced Leukemia Cell-Derived Exosomes Target Dendritic Cells to Induce Potent AntiLeukemic Immunity in a Mouse Model. Cancer Immunol Immunother (2017) 66:1321-31. doi: 10.1007/s00262-017-2028-5

47. Andre F, Schartz NE, Movassagh M, Flament C, Pautier P, Morice P, et al. Malignant Effusions and Immunogenic Tumour-Derived Exosomes. Lancet (2002) 360:295-305. doi: 10.1016/S0140-6736(02)09552-1

48. Hoshino A, Costa-Silva B, Shen T-L, Rodrigues G, Hashimoto A, Mark MT, et al. Tumour Exosome Integrins Determine Organotropic Metastasis. Nature (2015) 527:329-35. doi: 10.1038/nature15756

49. Tulkens J, De Wever O, Hendrix A. Analyzing Bacterial Extracellular Vesicles in Human Body Fluids by Orthogonal Biophysical Separation and Biochemical Characterization. Nat Protoc (2020) 15:40-67. doi: 10.1038/ s41596-019-0236-5

50. Brubaker SW, Bonham KS, Zanoni I, Kagan JC. Innate Immune Pattern Recognition: A Cell Biological Perspective. Annu Rev Immunol (2015) 33:257-90. doi: 10.1146/annurev-immunol-032414-112240

51. Abu N, Rus Bakarurraini NAA, Nasir SN. Extracellular Vesicles and DAMPs in Cancer: A Mini-Review. Front Immunol (2021) 12:740548. doi: 10.3389/ fimmu.2021.740548

52. Chow A, Zhou W, Liu L, Fong MY, Champer J, Van Haute D, et al. Macrophage Immunomodulation by Breast Cancer-Derived Exosomes Requires Toll-Like Receptor 2-Mediated Activation of NF-кB. Sci Rep (2014) 4:5750. doi: 10.1038/srep05750

53. Morrissey SM, Zhang F, Ding C, Montoya-Durango DE, Hu X, Yang C, et al. Tumor-Derived Exosomes Drive Immunosuppressive Macrophages in a Pre-Metastatic Niche Through Glycolytic Dominant Metabolic Reprogramming. Cell Metab (2021) 33(10):2040-58. doi: 10.1016/ j.cmet.2021.09.002
54. Fabbri M, Paone A, Calore F, Galli R, Gaudio E, Santhanam R, et al. MicroRNAs Bind to Toll-Like Receptors to Induce Prometastatic Inflammatory Response. Proc Natl Acad Sci USA (2012) 109:E2110-6. doi: 10.1073/pnas.1209414109

55. Murillo OD, Thistlethwaite W, Rozowsky J, Subramanian SL, Lucero R, Shah N, et al. exRNA Atlas Analysis Reveals Distinct Extracellular RNA Cargo Types and Their Carriers Present Across Human Biofluids. Cell (2019) 177:463-77.e15. doi: 10.1016/j.cell.2019.02.018

56. Kahlert C, Melo SA, Protopopov A, Tang J, Seth S, Koch M, et al. Identification of Double-Stranded Genomic DNA Spanning All Chromosomes With Mutated KRAS and P53 DNA in the Serum Exosomes of Patients With Pancreatic Cancer*. J Biol Chem (2014) 289:3869-75. doi: 10.1074/jbc.C113.532267

57. Haas T, Metzger J, Schmitz F, Heit A, Müller T, Latz E, et al. The DNA Sugar Backbone 2' Deoxyribose Determines Toll-Like Receptor 9 Activation. Immunity (2008) 28:315-23. doi: 10.1016/j.immuni.2008.01.013

58. Sansone P, Savini C, Kurelac I, Chang Q, Amato LB, Strillacci A, et al. Packaging and Transfer of Mitochondrial DNA via Exosomes Regulate Escape From Dormancy in Hormonal Therapy-Resistant Breast Cancer. Proc Natl Acad Sci (2017) 114:E9066-75. doi: 10.1073/pnas.1704862114

59. Bao D, Zhao J, Zhou X, Yang Q, Chen Y, Zhu J, et al. Mitochondrial FissionInduced mtDNA Stress Promotes Tumor-Associated Macrophage Infiltration and HCC Progression. Oncogene (2019) 38:5007-20. doi: 10.1038/s41388-019-0772-z

60. Zhang Q, Raoof M, Chen Y, Sumi Y, Sursal T, Junger W, et al. Circulating Mitochondrial DAMPs Cause Inflammatory Responses to Injury. Nature (2010) 464:104-7. doi: 10.1038/nature08780

61. Petros JA, Baumann AK, Ruiz-Pesini E, Amin MB, Sun CQ, Hall J, et al. mtDNA Mutations Increase Tumorigenicity in Prostate Cancer. Proc Natl Acad Sci USA (2005) 102:719-24. doi: 10.1073/pnas.0408894102

62. Dalpke AH, Lehner MD, Hartung T, Heeg K. Differential Effects of CpGDNA in Toll-Like Receptor-2/-4/-9 Tolerance and Cross-Tolerance. Immunology (2005) 116:203-12. doi: 10.1111/j.1365-2567.2005.02211.x

63. Esplin BL, Shimazu T, Welner RS, Garrett KP, Nie L, Zhang Q, et al. Chronic Exposure to a TLR Ligand Injures Hematopoietic Stem Cells. J Immunol (2011) 186:5367-75. doi: 10.4049/jimmunol.1003438

64. Mitroulis I, Ruppova K, Wang B, Chen L-S, Grzybek M, Grinenko T, et al. Modulation of Myelopoiesis Progenitors Is an Integral Component of Trained Immunity. Cell (2018) 172:147-61.e12. doi: 10.1016/j.cell.2017.11.034

65. Ji Z, He L, Regev A, Struhl K. Inflammatory Regulatory Network Mediated by the Joint Action of NF-kB, STAT3, and AP-1 Factors Is Involved in Many Human Cancers. Proc Natl Acad Sci (2019) 116:9453-62. doi: 10.1073/ pnas. 1821068116

66. Chalmin F, Ladoire S, Mignot G, Vincent J, Bruchard M, Remy-Martin J-P, et al. Membrane-Associated Hsp72 From Tumor-Derived Exosomes Mediates STAT3-Dependent Immunosuppressive Function of Mouse and Human Myeloid-Derived Suppressor Cells. J Clin Invest (2010) 120:457-71. doi: 10.1172/JCI40483

67. Gabrusiewicz K, Li X, Wei J, Hashimoto Y, Marisetty AL, Ott M, et al. Glioblastoma Stem Cell-Derived Exosomes Induce M2 Macrophages and PD-L1 Expression on Human Monocytes. OncoImmunology (2018) 7: e1412909. doi: 10.1080/2162402X.2017.1412909

68. Shen Y, Guo D, Weng L, Wang S, Ma Z, Yang Y, et al. Tumor-Derived Exosomes Educate Dendritic Cells to Promote Tumor Metastasis via HSP72/ HSP105-TLR2/TLR4 Pathway. Oncoimmunology (2017) 6. doi: 10.1080/ 2162402X.2017.1362527

69. Zhang X, Li F, Tang Y, Ren Q, Xiao B, Wan Y, et al. miR-21a in Exosomes From Lewis Lung Carcinoma Cells Accelerates Tumor Growth Through Targeting PDCD4 to Enhance Expansion of Myeloid-Derived Suppressor Cells. Oncogene (2020) 39:6354-69. doi: 10.1038/s41388-020-01406-9

70. Yang C, Dou R, Wei C, Liu K, Shi D, Zhang C, et al. Tumor-Derived Exosomal microRNA-106b-5p Activates EMT-Cancer Cell and M2-Subtype TAM Interaction to Facilitate CRC Metastasis. Mol Ther (2021) 29(6):2088107. doi: $10.1016 /$ j.ymthe.2021.02.006

71. Ying X, Wu Q, Wu X, Zhu Q, Wang X, Jiang L, et al. Epithelial Ovarian Cancer-Secreted Exosomal miR-222-3p Induces Polarization of TumorAssociated Macrophages. Oncotarget (2016) 7:43076-87. doi: 10.18632/ oncotarget.9246 
72. Chevillet JR, Kang Q, Ruf IK, Briggs HA, Vojtech LN, Hughes SM, et al. Quantitative and Stoichiometric Analysis of the microRNA Content of Exosomes. Proc Natl Acad Sci USA (2014) 111:14888-93. doi: 10.1073/ pnas. 1408301111

73. Costa-Silva B, Aiello NM, Ocean AJ, Singh S, Zhang H, Thakur BK, et al. Pancreatic Cancer Exosomes Initiate Pre-Metastatic Niche Formation in the Liver. Nat Cell Biol (2015) 17:816-26. doi: 10.1038/ncb3169

74. Peinado H, Alečković M, Lavotshkin S, Matei I, Costa-Silva B, MorenoBueno G, et al. Melanoma Exosomes Educate Bone Marrow Progenitor Cells Toward a Pro-Metastatic Phenotype Through MET. Nat Med (2012) 18:883-91. doi: 10.1038/nm.2753

75. Zhang L, Zhang S, Yao J, Lowery FJ, Zhang Q, Huang W-C, et al. Microenvironment-Induced PTEN Loss by Exosomal microRNA Primes Brain Metastasis Outgrowth. Nature (2015) 527:100-4. doi: 10.1038/ nature 15376

76. Ortiz A, Gui J, Zahedi F, Yu P, Cho C, Bhattacharya S, et al. An InterferonDriven Oxysterol-Based Defense Against Tumor-Derived Extracellular Vesicles. Cancer Cell (2019) 35:33-45.e6. doi: 10.1016/j.ccell.2018.12.001

77. Gao L, Wang L, Dai T, Jin K, Zhang Z, Wang S, et al. Tumor-Derived Exosomes Antagonize Innate Antiviral Immunity. Nat Immunol (2018) 19:233-45. doi: 10.1038/s41590-017-0043-5

78. Shi Y, Du L, Lv D, Li H, Shang J, Lu J, et al. Exosomal Interferon-Induced Transmembrane Protein 2 Transmitted to Dendritic Cells Inhibits Interferon Alpha Pathway Activation and Blocks Anti-Hepatitis B Virus Efficacy of Exogenous Interferon Alpha. Hepatology (2019) 69:2396-413. doi: 10.1002/hep.30548

79. Alicea-Torres K, Sanseviero E, Gui J, Chen J, Veglia F, Yu Q, et al. Immune Suppressive Activity of Myeloid-Derived Suppressor Cells in Cancer Requires Inactivation of the Type I Interferon Pathway. Nat Commun (2021) 12:1717. doi: 10.1038/s41467-021-22033-2

80. van de Wall S, Santegoets KCM, van Houtum EJH, Büll C, Adema GJ. Sialoglycans and Siglecs Can Shape the Tumor Immune Microenvironment. Trends Immunol (2020) 41:274-85. doi: 10.1016/j.it.2020.02.001

81. Lübbers J, Rodríguez E, van Kooyk Y. Modulation of Immune Tolerance via Siglec-Sialic Acid Interactions. Front Immunol (2018) 9:2807. doi: 10.3389/ fimmu.2018.02807

82. Crocker PR, Paulson JC, Varki A. Siglecs and Their Roles in the Immune System. Nat Rev Immunol (2007) 7:255-66. doi: 10.1038/nri2056

83. Christianson HC, Svensson KJ, van Kuppevelt TH, Li J-P, Belting M. Cancer Cell Exosomes Depend on Cell-Surface Heparan Sulfate Proteoglycans for Their Internalization and Functional Activity. Proc Natl Acad Sci (2013) 110:17380-5. doi: 10.1073/pnas.1304266110

84. Saunderson SC, Dunn AC, Crocker PR, McLellan AD. CD169 Mediates the Capture of Exosomes in Spleen and Lymph Node. Blood (2014) 123:208-16. doi: 10.1182/blood-2013-03-489732

85. Ravishankar B, Shinde R, Liu H, Chaudhary K, Bradley J, Lemos HP, et al. Marginal Zone CD169+ Macrophages Coordinate Apoptotic Cell-Driven Cellular Recruitment and Tolerance. Proc Natl Acad Sci (2014) 111:4215-20. doi: $10.1073 /$ pnas.1320924111

86. Gummuluru S, Ramirez N-GP, Akiyama H. CD169-Dependent CellAssociated HIV-1 Transmission: A Driver of Virus Dissemination. J Infect Dis (2014) 210:S641-7. doi: 10.1093/infdis/jiu442

87. Barral P, Polzella P, Bruckbauer A, van Rooijen N, Besra GS, Cerundolo V, et al. CD169+ Macrophages Present Lipid Antigens to Mediate Early Activation of Invariant NKT Cells in Lymph Nodes. Nat Immunol (2010) 11:303-12. doi: 10.1038/ni.1853

88. Zheng Q, Hou J, Zhou Y, Yang Y, Xie B, Cao X. Siglec1 Suppresses Antiviral Innate Immune Response by Inducing TBK1 Degradation via the Ubiquitin Ligase TRIM27. Cell Res (2015) 25:1121-36. doi: 10.1038/cr.2015.108

89. Loschko J, Heink S, Hackl D, Dudziak D, Reindl W, Korn T, et al. Antigen Targeting to Plasmacytoid Dendritic Cells via Siglec-H Inhibits Th CellDependent Autoimmunity. J Immunol (2011) 187:6346-56. doi: 10.4049/ jimmunol.1102307

90. Chen G-Y, Brown NK, Zheng P, Liu Y. Siglec-G/10 in Self-Nonself Discrimination of Innate and Adaptive Immunity. Glycobiology (2014) 24:800-6. doi: 10.1093/glycob/cwu068

91. Rodriguez E, Boelaars K, Brown K, Eveline Li RJ, Kruijssen L, Bruijns SCM, et al. Sialic Acids in Pancreatic Cancer Cells Drive Tumour-Associated
Macrophage Differentiation via the Siglec Receptors Siglec-7 and Siglec-9. Nat Commun (2021) 12:1270. doi: 10.1038/s41467-021-21550-4

92. Chow A, Lucas D, Hidalgo A, Méndez-Ferrer S, Hashimoto D, Scheiermann C, et al. Bone Marrow CD169+ Macrophages Promote the Retention of Hematopoietic Stem and Progenitor Cells in the Mesenchymal Stem Cell Niche. J Exp Med (2011) 208:261-71. doi: 10.1084/jem.20101688

93. Chow A, Huggins M, Ahmed J, Hashimoto D, Lucas D, Kunisaki Y, et al. CD $169^{+}$Macrophages Provide a Niche Promoting Erythropoiesis Under Homeostasis and Stress. Nat Med (2013) 19:429-36. doi: 10.1038/nm.3057

94. Witwer KW, Théry C. Extracellular Vesicles or Exosomes? On Primacy, Precision, and Popularity Influencing a Choice of Nomenclature. J Extracell Vesicles (2019) 8. doi: 10.1080/20013078.2019.1648167

95. Latham SL, Tiberti N, Gokoolparsadh N, Holdaway K, Olivier Couraud P, Grau GER, et al. Immuno-Analysis of Microparticles: Probing at the Limits of Detection. Sci Rep (2015) 5:16314. doi: 10.1038/srep16314

96. Turpin D, Truchetet M-E, Faustin B, Augusto J-F, Contin-Bordes C, Brisson A, et al. Role of Extracellular Vesicles in Autoimmune Diseases. Autoimmun $\operatorname{Rev}(2015)$ 15:174-83. doi: 10.1016/j.autrev.2015.11.004

97. Sellam J, Proulle V, Jüngel A, Ittah M, Miceli Richard C, Gottenberg J-E, et al. Increased Levels of Circulating Microparticles in Primary Sjögren's Syndrome, Systemic Lupus Erythematosus and Rheumatoid Arthritis and Relation With Disease Activity. Arthritis Res Ther (2009) 11:R156. doi: 10.1186/ar2833

98. Shinde R, Hezaveh K, Halaby MJ, Kloetgen A, Chakravarthy A, da Silva Medina $\mathrm{T}$, et al. Apoptotic Cell-Induced AhR Activity Is Required for Immunological Tolerance and Suppression of Systemic Lupus Erythematosus in Mice and Humans. Nat Immunol (2018) 19:571-82. doi: 10.1038/s41590-018-0107-1

99. McGaha TL, Karlsson MCI. Apoptotic Cell Responses in the Splenic Marginal Zone: A Paradigm for Immunologic Reactions to Apoptotic Antigens With Implications for Autoimmunity. Immunol Rev (2016) 269:26-43. doi: 10.1111/imr.12382

100. Kim S, Chen Z, Essani AB, Elshabrawy HA, Volin MV, Volkov S, et al. Identification of a Novel Toll-Like Receptor 7 Endogenous Ligand in Rheumatoid Arthritis Synovial Fluid That Can Provoke Arthritic Joint Inflammation. Arthritis Rheumatol Hoboken NJ (2016) 68:1099-110. doi: 10.1002/art.39544

101. Sisirak V, Sally B, D’Agati V, Martinez-Ortiz W, Özçakar ZB, David J, et al. Digestion of Chromatin in Apoptotic Cell Microparticles Prevents Autoimmunity. Cell (2016) 166:88-101. doi: 10.1016/j.cell.2016.05.034

102. Harris HE, Andersson U, Pisetsky DS. HMGB1: A Multifunctional Alarmin Driving Autoimmune and Inflammatory Disease. Nat Rev Rheumatol (2012) 8:195-202. doi: 10.1038/nrrheum.2011.222

103. Ryu C, Walia A, Ortiz V, Sun H, Winkler J, Kanyo J, et al. Herzog, Bioactive Plasma Mitochondrial DNA Is Associated With Disease Progression in Scleroderma-Associated Interstitial Lung Disease. Arthritis Rheumatol (2020) 72:1905-15. doi: 10.1002/art.41418

104. Uccellini MB, Avalos AM, Marshak-Rothstein A, Viglianti GA. Toll-Like Receptor-Dependent Immune Complex Activation of B Cells and Dendritic Cells. Methods Mol Biol Clifton NJ (2009) 517:363-80. doi: 10.1007/978-159745-541-1_22

105. Burbano C, Villar-Vesga J, Orejuela J, Muñoz C, Vanegas A, Vásquez G, et al. Potential Involvement of Platelet-Derived Microparticles and Microparticles Forming Immune Complexes During Monocyte Activation in Patients With Systemic Lupus Erythematosus. Front Immunol (2018) 9:322. doi: 10.3389/ fimmu.2018.00322

106. Burbano C, Villar-Vesga J, Vásquez G, Muñoz-Vahos C, Rojas M, Castaño D. Proinflammatory Differentiation of Macrophages Through Microparticles That Form Immune Complexes Leads to T- and B-Cell Activation in Systemic Autoimmune Diseases. Front Immunol (2019) 10:2058. doi: 10.3389/fimmu.2019.02058

107. Jing C, Castro-Dopico T, Richoz N, Tuong ZK, Ferdinand JR, Lok LSC, et al. Macrophage Metabolic Reprogramming Presents a Therapeutic Target in Lupus Nephritis. Proc Natl Acad Sci (2020) 117:15160-71. doi: 10.1073/ pnas. 2000943117

108. Rahman MJ, Regn D, Bashratyan R, Dai YD. Exosomes Released by IsletDerived Mesenchymal Stem Cells Trigger Autoimmune Responses in NOD Mice. Diabetes (2014) 63:1008-20. doi: 10.2337/db13-0859 
109. Hasilo CP, Negi S, Allaeys I, Cloutier N, Rutman AK, Gasparrini M, et al. Presence of Diabetes Autoantigens in Extracellular Vesicles Derived From Human Islets. Sci Rep (2017) 7:5000. doi: 10.1038/s41598-017-04977-y

110. Salama A, Fichou N, Allard M, Dubreil L, De Beaurepaire L, Viel A, et al. MicroRNA-29b Modulates Innate and Antigen-Specific Immune Responses in Mouse Models of Autoimmunity. PloS One (2014) 9. doi: 10.1371/ journal.pone. 0106153

111. Sun Y, Zhou Y, Shi Y, Zhang Y, Liu K, Liang R, et al. Expression of miRNA29 in Pancreatic $\beta$ Cells Promotes Inflammation and Diabetes via TRAF3. Cell Rep (2021) 34:108576. doi: 10.1016/j.celrep.2020.108576

112. Quintana FJ, Murugaiyan G, Farez MF, Mitsdoerffer M, Tukpah A-M, Burns EJ, et al. An Endogenous Aryl Hydrocarbon Receptor Ligand Acts on Dendritic Cells and T Cells to Suppress Experimental Autoimmune Encephalomyelitis. Proc Natl Acad Sci USA (2010) 107:20768-73. doi: 10.1073/pnas.1009201107

113. Chronopoulos A, Kalluri R. Emerging Role of Bacterial Extracellular Vesicles in Cancer. Oncogene (2020) 39:6951-60. doi: 10.1038/s41388-020-01509-3

114. Lucien F, Lac V, Billadeau DD, Borgida A, Gallinger S, Leong HS. Glypican-1 and Glycoprotein 2 Bearing Extracellular Vesicles do Not Discern Pancreatic Cancer From Benign Pancreatic Diseases. Oncotarget (2019) 10:1045-55. doi: $10.18632 /$ oncotarget. 26620

115. Mobarrez F, Vikerfors A, Gustafsson JT, Gunnarsson I, Zickert A, Larsson A, et al. Microparticles in the Blood of Patients With Systemic Lupus Erythematosus (SLE): Phenotypic Characterization and Clinical Associations. Sci Rep (2016) 6:36025. doi: 10.1038/srep36025

116. Jayaseelan VP. Emerging Role of Exosomes as Promising Diagnostic Tool for Cancer. Cancer Gene Ther (2020) 27:395-8. doi: 10.1038/s41417-019-0136-4

117. Back MJ, Ha HC, Fu Z, Choi JM, Piao Y, Won JH, et al. Activation of Neutral Sphingomyelinase 2 by Starvation Induces Cell-Protective Autophagy via an Increase in Golgi-Localized Ceramide. Cell Death Dis (2018) 9:1-18. doi: 10.1038/s41419-018-0709-4

118. Datta A, Kim H, McGee L, Johnson AE, Talwar S, Marugan J, et al. HighThroughput Screening Identified Selective Inhibitors of Exosome Biogenesis and Secretion: A Drug Repurposing Strategy for Advanced Cancer. Sci Rep (2018) 8:8161. doi: 10.1038/s41598-018-26411-7

119. Qin X, Wang J, Wang X, Liu F, Jiang B, Zhang Y. Targeting Rabs as a Novel Therapeutic Strategy for Cancer Therapy. Drug Discov Today (2017) 22:1139-47. doi: 10.1016/j.drudis.2017.03.012

120. Li X, Wang H, Ni Q, Tang Z, Ni J, Xu L, et al. Effects of Silencing Rab27a Gene on Biological Characteristics and Chemosensitivity of Non-Small Cell Lung Cancer. Oncotarget (2017) 8:94481-92. doi: 10.18632/oncotarget.21782

121. Murugesan G, Weigle B, Crocker PR. Siglec and Anti-Siglec Therapies. Curr Opin Chem Biol (2021) 62:34-42. doi: 10.1016/j.cbpa.2021.01.001

122. Edgar LJ, Kawasaki N, Nycholat CM, Paulson JC. Targeted Delivery of Antigen to Activated CD169+ Macrophages Induces Bias for Expansion of CD8+ T Cells. Cell Chem Biol (2019) 26:131-6.e4. doi: 10.1016/j.chembiol.2018.10.006

123. Petroni G, Buqué A, Zitvogel L, Kroemer G, Galluzzi L. Immunomodulation by Targeted Anticancer Agents. Cancer Cell (2021) 39:310-45. doi: 10.1016/ j.ccell.2020.11.009

124. Kelly MG, Alvero AB, Chen R, Silasi D-A, Abrahams VM, Chan S, et al. TLR-4 Signaling Promotes Tumor Growth and Paclitaxel Chemoresistance in Ovarian Cancer. Cancer Res (2006) 66:3859-68. doi: 10.1158/0008-5472.CAN-05-3948

125. Yin C, Kim Y, Argintaru D, Heit B. Rab17 Mediates Differential Antigen Sorting Following Efferocytosis and Phagocytosis. Cell Death Dis (2016) 7: e2529. doi: 10.1038/cddis.2016.431

126. Lewis ND, Sia CL, Kirwin K, Haupt S, Mahimkar G, Zi T, et al. Exosome Surface Display of IL12 Results in Tumor-Retained Pharmacology With Superior Potency and Limited Systemic Exposure Compared With
Recombinant IL12. Mol Cancer Ther (2021) 20:523-34. doi: 10.1158/15357163.MCT-20-0484

127. Spadaro F, Lapenta C, Donati S, Abalsamo L, Barnaba V, Belardelli F, et al. IFN- $\alpha$ Enhances Cross-Presentation in Human Dendritic Cells by Modulating Antigen Survival, Endocytic Routing, and Processing. Blood (2012) 119:1407-17. doi: 10.1182/blood-2011-06-363564

128. Jang SC, Economides KD, Moniz RJ, Sia CL, Lewis N, McCoy C, et al. ExoSTING, an Extracellular Vesicle Loaded With STING Agonists, Promotes Tumor Immune Surveillance. Commun Biol (2021) 4:1-17. doi: $10.1038 / \mathrm{s} 42003-021-02004-5$

129. Kitai Y, Kawasaki T, Sueyoshi T, Kobiyama K, Ishii KJ, Zou J, et al. DNAContaining Exosomes Derived From Cancer Cells Treated With Topotecan Activate a STING-Dependent Pathway and Reinforce Antitumor Immunity. J Immunol (2017) 198:1649-59. doi: 10.4049/jimmunol.1601694

130. Nabet BY, Qiu Y, Shabason JE, Wu TJ, Yoon T, Kim BC, et al. Exosome RNA Unshielding Couples Stromal Activation to Pattern Recognition Receptor Signaling in Cancer. Cell (2017) 170:352-66.e13. doi: 10.1016/ j.cell.2017.06.031

131. Casella G, Rasouli J, Boehm A, Zhang W, Xiao D, Ishikawa LLW, et al. Oligodendrocyte-Derived Extracellular Vesicles as Antigen-Specific Therapy for Autoimmune Neuroinflammation in Mice. Sci Transl Med (2020) 12: eaba0599. doi: 10.1126/scitranslmed.aba0599

132. Zitvogel L, Regnault A, Lozier A, Wolfers J, Flament C, Tenza D, et al. Eradication of Established Murine Tumors Using a Novel Cell-Free Vaccine: Dendritic Cell-Derived Exosomes. Nat Med (1998) 4:594-600. doi: 10.1038/ nm0598-594

133. Gu X, Erb U, Büchler MW, Zöller M. Improved Vaccine Efficacy of Tumor Exosome Compared to Tumor Lysate Loaded Dendritic Cells in Mice. Int $J$ Cancer (2015) 136:E74-84. doi: 10.1002/ijc.29100

134. Hiltbrunner S, Larssen P, Eldh M, Martinez-Bravo M-J, Wagner AK, Karlsson MCI, et al. Exosomal Cancer Immunotherapy Is Independent of MHC Molecules on Exosomes. Oncotarget (2016) 7:38707-17. doi: 10.18632/ oncotarget.9585

135. Wahlund CJE, Güclüler G, Hiltbrunner S, Veerman RE, Näslund TI, Gabrielsson S. Exosomes From Antigen-Pulsed Dendritic Cells Induce Stronger Antigen-Specific Immune Responses Than Microvesicles In Vivo. Sci Rep (2017) 7:17095. doi: 10.1038/s41598-017-16609-6

136. Wolfers J, Lozier A, Raposo G, Regnault A, Théry C, Masurier C, et al. Tumor-Derived Exosomes Are a Source of Shared Tumor Rejection Antigens for CTL Cross-Priming. Nat Med (2001) 7:297-303. doi: $10.1038 / 85438$

Conflict of Interest: The authors declare that the research was conducted in the absence of any commercial or financial relationships that could be construed as a potential conflict of interest.

Publisher's Note: All claims expressed in this article are solely those of the authors and do not necessarily represent those of their affiliated organizations, or those of the publisher, the editors and the reviewers. Any product that may be evaluated in this article, or claim that may be made by its manufacturer, is not guaranteed or endorsed by the publisher.

Copyright () 2022 Makhijani and McGaha. This is an open-access article distributed under the terms of the Creative Commons Attribution License (CC BY). The use, distribution or reproduction in other forums is permitted, provided the original author(s) and the copyright owner(s) are credited and that the original publication in this journal is cited, in accordance with accepted academic practice. No use, distribution or reproduction is permitted which does not comply with these terms. 